\title{
The Effect of Posture on the Intraocular Pressure and Pulsatile Ocular Blood Flow in Patients with Non- arteritic Anterior Ischaemic Optic Neuropathy
}

\author{
C. B. JAMES and S. E. SMITH \\ London
}

\begin{abstract}
Summary
Intraocular pressure (IOP) and pulsatile ocular bloodflow (POBF) have been recorded in 15 patients with unilateral non-arteritic anterior ischaemic optic neuropathy (na-AION) and in 28 healthy subjects of comparable age. Measurements were obtained in both the upright and lying postures with a pneumotonometer linked to a Langham ocular bloodflow system.

By comparison with the healthy subjects, patients with na-AION were found to have a significantly greater postural pressure change in IOP $(3.9 \pm 0.4 \mathrm{mmHg}$ in the affected eye and $3.6 \pm 0.6 \mathrm{mmHg}$ in the unaffected eye of the patients with na-AION compared to $2.2 \pm 0.4 \mathrm{mmHg}$ in the right eye of the healthy subjects $\mathrm{P}<0.01$ and $<0.05$ respectively). There was no significant difference between the IOP in the affected and unaffected eyes of patients with na-AION nor between this group and the healthy subjects in either posture. Pulsatile ocular bloodflow measurements were similar in both groups and in both eyes of the patients with na-AION. In both groups POBF fell significantly on lying down (healthy right eyes $-84 \pm 16 \mathrm{ul} / \mathrm{min} \mathbf{p}<0.01$, na-AION affected eye $-84 \pm 24 \mathrm{ul} / \mathrm{min} p<0.01$, unaffected eye $-83 \pm 26 \mathrm{ul} / \mathrm{min}$ $p<0.001$ ). These figures represent decrements of $19 \%$ in all groups.

These findings suggest that assumption of the supine posture may be associated with a reduction in the pulsatile component of ocular perfusion. The importance of this in the pathogenesis of na-AION is discussed.
\end{abstract}

Non-arteritic anterior ischaemic optic neuropathy (na-AION) results from ischaemia of the retrolamina part of the optic nerve head. ${ }^{1}$ Classically it causes painless loss of vision or visual field, often noticed by the patient on waking. Acutely there is swelling of the optic disc. This is associated with peripapillary haemorrhages and followed after some weeks by pallor of the disc. Experimental work has shown that the clinical picture of the disease can be produced by occlusion of one or more of the posterior ciliary arteries. ${ }^{2}$ Pathological data on the clinical condition in man is scant. ${ }^{3}$ To date there is no documented evidence of posterior ciliary artery occlusion.

In the absence of overt arterial occlusion ischaemia presumably results from a reduction of ocular perfusion. This is dependent both on the pressure of blood in the supplying arteries and the IOP. The role of an elevation of intraocular pressure in na-AION remains controversial. Reports of an increased IOP in

From: Division of Pharmacological Sciences and Toxicology, United Medical and Dental Schools of Guy's and St Thomas' Hospital, St Thomas' Hospital, London SE1 7EH

Correspondence to: Mr C. B. James, Department of Clinical Pharmacology, St Thomas' Hospital, London SE1 7EH. 
some affected eyes of patients with na-AION have been made. ${ }^{4,5,6}$

Work using ocular pneumoplethysmography has confirmed a reduced ocular blood flow in patients with acute anterior ischaemic optic neuropathy associated with temporal arteritis. ${ }^{7}$ This has been seen in both the affected and the unaffected eye. A reduction in the amplitude of the ocular pulse has also been reported in this condition. ${ }^{8,9}$ These observations concur with the pathological data that is available in this form of ischaemic neuropathy where involvement of posterior ciliary and short ciliary vessels in the arteritic process is seen. ${ }^{10}$

The aims of this study have been twofold: firstly to determine the magnitude of the postural change in IOP in patients with unilateral na-AION; secondly to determine if POBF is reduced in na-AION and to assess the effect of change in posture in POBF in these patients.

\section{Methods}

\section{Patients}

Fifteen patients with unilateral na-AION were identified from the records of the eye department at St Thomas' Hospital. The mean age was 64.8 years with a range of 43 to 79 years. There were eight females and seven males. Five were on treatment for hypertension, four with beta adrenoceptor blocking drugs. Three of the group were diabetic, none with significant retinopathy. All had been admitted for thorough examination and investigation. Diagnosis was based on a typical history, visual field examination and optic disc appearance. The mean time between development of na-AION and examination was 6.5 years with a range of 0.3 to 14.3 years. The mean spherical refraction of this group was $1.4 \pm 0.5$ dioptres.

The healthy subjects comprised members of staff and visitors to the hospital. No one in this group had a history of previous systemic or ocular diseases. Twenty eight people, five male and twenty-three female, were measured with a mean age of 51.3 years and a range of 29 to 73 years. The mean spherical equivalent refraction of this group was $0.2 \pm 0.3$ dioptres.

Subjects in both groups were measured randomly between the hours of 9.00 am and $4.00 \mathrm{pm}$.

\section{Measurements}

Intraocular pressure and POBF were measured in both eyes with a pneumotonometer linked to a Langham Ocular Blood Flow System after instillation of local anaesthetic (Benoxinate) into both eyes. POBF was calculated in the manner described by Silver and Langham. ${ }^{11,12}$ This relies on converting the pressure pulse into a volume pulse by means of a previously calculated pressure/volume relationship. ${ }^{13} \mathrm{~A}$ figure for the pulse volume is thus obtained. Multiplication of the pulse volume by the heart rate yields the pulsatile ocular blood flow. The pulse amplitude represents the difference between the pressure at the lowest and highest part of the pressure pulse. Intraocular pressure was calculated as the mean of the lowest and highest pressure in the pulse. The patient was linked to an ECG machine which was run simultaneously with the pneumotonometer to allow heart rate to be measured simultaneously with the ocular pulse wave.

Blood pressure was recorded with an autosphygmomanometer (Takeda Medical) using an arm cuff level with the heart in both upright and supine positions. Mean blood pressure was calculated as diastolic pressure $+1 / 3$ of the pulse pressure.

The following protocol was observed for both groups of subjects. Refractive and slit lamp examination and fundoscopy was first performed on all subjects. Prior to measurement the subject rested sitting for 10 minutes. This was followed by a period of five minutes standing. Measurement of blood pressure and pneumotonometric recordings were then made. The subject then lay down 15 minutes using one pillow as a headrest and the procedure was repeated.

\section{Statistical Analysis}

Differences between subjects were assessed with unpaired t-tests. Within subject differences were analysed with paired t-tests. Results are expressed as the mean \pm the standard error of the mean (SEM).

\section{Results}

Intraocular Pressure

In healthy subjects there was no significant 
Table I Postural changes in intraocular pressure (IOP), pulse amplitude (PA), ocular pulse volume (PV) and pulsatile ocular bloodflow $(P O B F)$ in both the affected and unaffected eye of subjects with unilateral na-AION and the right eye of healthy subjects. (SEM = standard error of the mean)

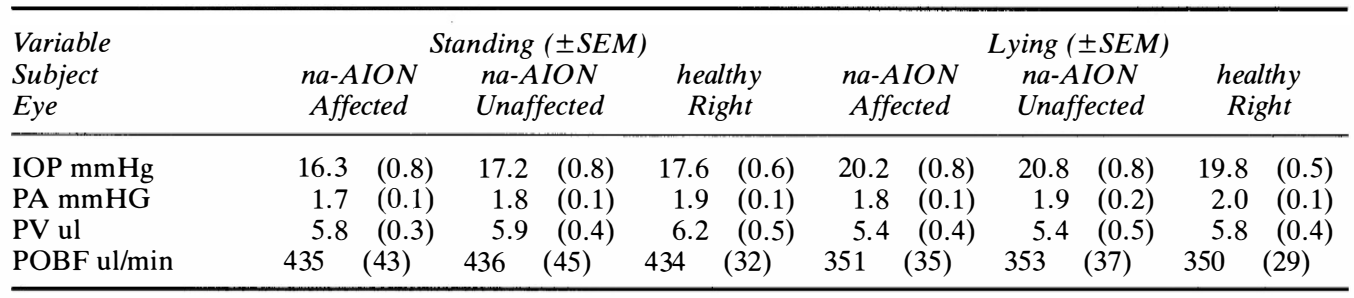

difference between the right and left eyes; thus only the data for the right eye is given. There was no significant difference in the IOP between the two groups in either the standing or the lying position (Table I). Both showed a significant postural rise in intraocular pressure on lying down (Fig. 1). In the right eye of the healthy group this was $2.2 \pm 0.4 \mathrm{mmHg}$ $(\mathrm{P}<0.001)$. The rise in the na-AION group was $3.9 \pm 0.4 \mathrm{mmHg}$ in the affected eye and $3.6 \pm 0.6 \mathrm{mmHg}$ in the unaffected eye $(\mathrm{P}<0.001$ for both eyes $)$. The difference in the postural change in IOP between the healthy group and the subjects with na-AION was significant $(\mathrm{P}<0.01$ for the affected eye and $\mathrm{P}<0.05$ for the unaffected eye).

\section{Pulsatile Ocular Bloodflow}

There was no significant difference in POBF between the affected and the unaffected eyes of subjects with na-AION nor was there any difference between either eye of this group of subjects and the right eyes of the healthy group (Table I). In both healthy subjects and subjects with na-AION there was a postural fall in POBF (Fig. 2).

In the healthy group $-84 \pm 16 \mathrm{ul} / \mathrm{min}$

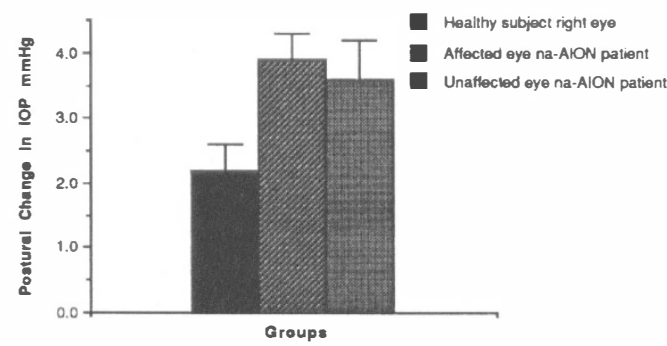

Fig. 1 Postural changes in intraocular pressure in the right eye of healthy subjects and affected and unaffected eyes of patients with na-AION (mean $\pm S E M)$.
$(\mathrm{P}<0.01)$, in the affected eye of na-AION subjects $-84 \pm 24 \mathrm{ul} / \mathrm{min}(\mathrm{P}<0.01)$ and in the unaffected eye $-83 \pm 26 \mathrm{ul} / \mathrm{min}(\mathrm{P}<0.001)$.

There was no difference between the two eyes of subjects with unilateral na-AION in the pulse amplitude of the intraocular pressure pulse nor was there any difference in the pulse volume. The measurements in these subjects were the same as in the healthy group (Table I).

\section{Systemic Blood Pressure}

A significant difference in mean blood pressure between the two groups was found (Fig. 3 ). The mean standing blood pressure in the healthy group was $98 \pm 2.2 \mathrm{mmHg}$ and in the na-AION group $111 \pm 3.7 \mathrm{mmHg}(\mathrm{P}<0.001)$. On lying down the mean blood pressure fell in the healthy group to $90 \pm 2.1 \mathrm{mmHg}$ and in the na-AION group to $104 \pm 3.4 \mathrm{mmHg}$. The postural fall in blood pressure in both groups was significant $(\mathrm{P}<0.05$ for the na-AION group, $\mathrm{P}<0.001$ for the healthy group).

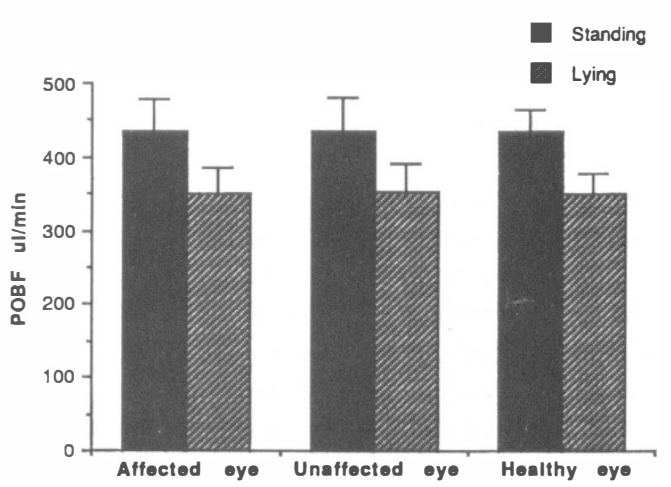

Fig. 2 Postural changes in POBF in healthy subjects and the affected and unaffected eyes of patients with na$A I O N$ (mean $\pm S E M)$. 


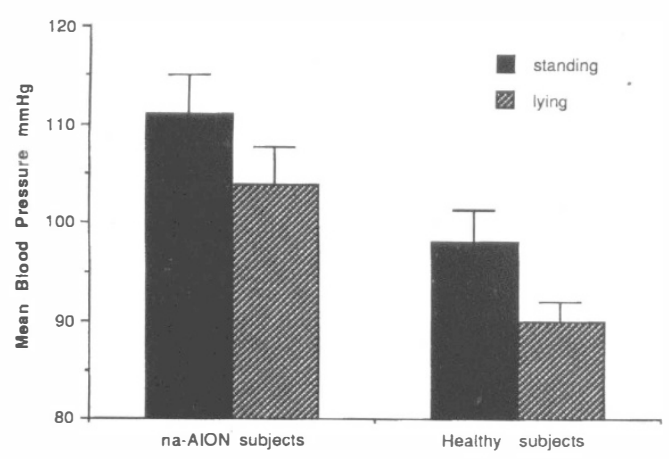

Fig. 3 Postural changes in mean blood pressure in healthy subjects and patients with na-AION (mean \pm SEM).

There was no significant difference in pulse rate between the two groups in either posture (Fig. 4) but again in both groups a significant reduction was seen on lying down $8 \pm 1.8$ beats $/ \mathrm{min} \mathrm{P}<0.001$ in the na-AION group, $11 \pm 1$ beats/min $\mathrm{P}<0.001$ in the healthy group).

\section{Discussion}

Although both the clinical and pathological appearance of na-AION can be mimicked by experimental occlusion of the posterior ciliary vessels it is far from clear what the pathogenesis of this often bilateral disease is in man. Structural changes causing crowding at the optic nerve ${ }^{14,15,16}$ as well as reduced perfusion due either to vascular abnormalities $^{17,18,19,20,21}$ or raised IOP ${ }^{4,5,6,22}$ have all been suggested as having a role in the pathogenesis of the condition. An increase in the incidence of hypertension and diabetes, both of which have pathological effects on the micro-circulation, has also been reported. ${ }^{23,24}$ Olver et al. $^{25}$ using microvascular corrosion casting techniques have demonstrated an altitudinal vascular supply to the retrolaminar optic nerve in which a reduction in perfusion pressure might cause a selective infarction of part of the optic nerve producing the typical altitudinal field defect. Furthermore as there is such an enormous variation in the anatomy of the blood supply to the anterior optic disc itself $^{26}$ different factors may assume greater importance in the individual patient. Relatively small changes in the perfusion of the retrolaminar optic nerve may thus be of great importance in causing ischaemia.
The results of this study have shown that contrary to the findings of $\mathrm{Katz}^{4}$ there appears to be no significant difference in IOP either between the affected and unaffected eyes of patients with na-AION or between these patients and healthy subjects. There is, however, a significantly larger difference in the postural change in IOP in patients with naAION on changing from the standing to the lying position. Williams et al. $^{27}$ reported an abnormal postural rise in IOP in hypertensive and diabetic patients. The mean blood pressure of the na-AION group was significantly higher than the control group, indeed five of these patients were on medication for hypertension. The increased mean blood pressure in the na-AION subjects may thus account for the increased postural pressure rise observed.

There has been some debate about the importance of an abnormality in IOP as a contributory factor in the pathogenesis of naAION. ${ }^{4,5,6}$ A sudden rise in IOP may be of importance if a critical state of perfusion in the retrolamina disc already exists. A similar mechanism has been postulated for the pathogenesis of the disease when it is seen soon after cataract surgery. ${ }^{22}$

Quantitive measurement of ocular blood flow using this technique is open to criticism. The pneumotonometer itself has been found to give pressure measurements that correlate well with the Goldmann tonometer. ${ }^{28}$ The pulse amplitude of the pressure pulse, however, may be dependent on the initial ocular volume and hence in part be dependent on the

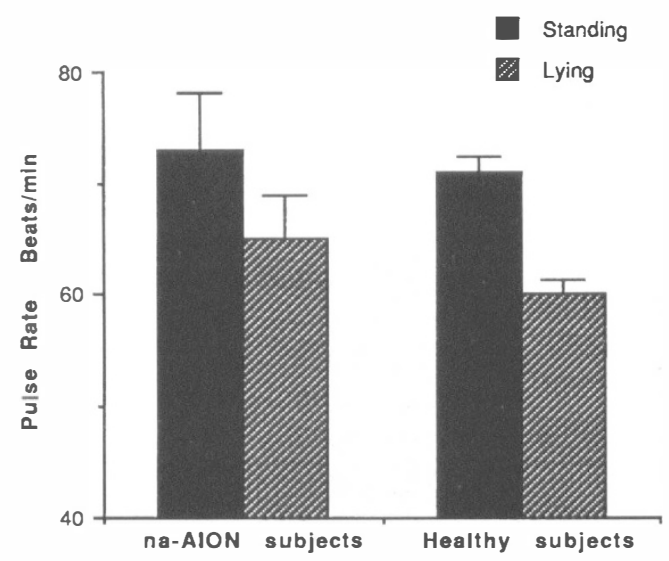

Fig. 4 Postural changes in the pulse rate of healthy subjects and patients with na-AION (mean $\pm S E M)$. 
refractive state of the eye with more hypermetropic individuals having a bigger pulse amplitude. ${ }^{29,30}$ The difference in our study between the refraction of the healthy subjects and those patients with na-AION was only 1.2 dioptres. Work is currently being undertaken in this department to evaluate more fully the relationship between pulse amplitude, POBF and axial length of the eye.

No difference in POBF was found either between affected and unaffected eyes of patients with na-AION or between these patients and healthy subjects. The mean blood pressure of the na-AION group was significantly higher than that of the healthy group, however. As there was no significant difference in IOP between the two groups perfusion pressure in the na-AION group should be greater. The similarity of POBF in the two groups despite this expected elevation of perfusion pressure in the na-AION group may reflect the increased peripheral vascular resistance seen in hypertension. A difference in ocular vascular resistance between the two groups will complicate the comparison between them for it may alter the relationship between pulsatile and non-pulsatile flow. A comparison between the affected and unaffected eyes of the na-AION group will circumvent this difficulty.

No asymmetry was noted between the two eyes in patients with unilateral na-AION. This suggests the absence of major occlusive intra or extra ocular vascular disease on the affected side. A transient vascular occlusion during the acute phase of na-AION cannot, however, be excluded.

There was a marked and similar postural reduction in POBF on lying down in both groups (Fig. 2) of some 19\%. The pulse volume was not significantly altered when posture changed although all groups showed a slight decrease (Table I). The reduction in POBF was associated both with a reduced pulse rate (Fig. 4) in the supine position and a reduction in mean blood pressure (Fig. 3). It must be remembered, however, that this technique is measuring only the pulsatile component of ocular bloodflow. There may well be a change in the ratio of pulsatile to nonpulsatile flow on changing posture. If the change in POBF does reflect a change in total bloodflow the reduction on assuming the supine posture observed here may be of importance in the pathogenesis of na-AION. The micro-circulation to the retrolaminar part of the disc may already be compromised by structural factors or pathological vascular changes and this reduction in flow may be sufficient to cause ischaemia of the optic nerve head.

\section{Conclusion}

A pneumotonometer linked to a Langham Ocular Blood Flow System has been used to measure the postural change in IOP and to derive a measurement of POBF in healthy subjects and patients with na-AION. A significant increase in the postural rise in patients with na-AION has been found. POBF is reduced both in healthy subjects and patients with na-AION on lying down. If this postural reduction in $\mathrm{POBF}$ reflects a reduction in bloodflow as a whole this together with a rise in IOP may result in reduced perfusion of the optic nerve head in the supine position. Assumption of the supine position may thus result in a critical state of perfusion at the optic nerve head. It is of interest in this respect that patients often first notice symptoms of the condition on waking when not only will they have been supine but their pulse rate and blood pressure will also have been reduced, possibly for some hours.

We thank the Medical Eye Unit at St Thomas' Hospital for allowing us to study their patients; Karen Clark and Raymond Allen for technical help and Jan Andrews for secretarial assistance. $\mathrm{CBJ}$ is supported by the special trustees of St Thomas' Hospital. Financial support for the study was also kindly provided by the Royal National Institute for the Blind. The Langham Ocular Bloodflow System was kindly donated by Dispersa UK Ltd.

\section{References}

${ }^{1}$ Hayreh SS: Anterior ischaemic optic neuropathy I. Terminology and pathogenesis. Br J Ophthalmol 1974, 58: 955-63.

${ }^{2}$ Hayreh SS and Baines JAB: Occlusion of the posterior ciliary artery III. Effects on the optic nerve head. Br J Ophthalmol 1972, 56: 754-64.

${ }^{3}$ Knox DL and Duke JR: Slowly progressive ischaemic optic neuropathy. Tr Am Acad Ophth and Otol 1971, 75: 1065-8.

${ }^{4}$ Katz B, Weinreb RN, Wheeler DT, Klauber MR: Anterior ischaemic optic neuropathy and intraocular pressure. Br J Ophthalmol 1990, 74: 99-102. 
${ }^{5}$ Tomask RL and Remler BF: Anterior ishaemic optic neuropathy and increased intraocular pressure. J Clin Neuro-ophthalmol 1989, 9: 116-18.

${ }^{6}$ Foulds WS: Visual disturbances in systemic disorders: Optic neuropathy and systemic disease. Trans Ophthalmol Soc UK 1969, 89: 125-46.

${ }^{7}$ Bosley TM, Savino PJ, Sergott RC, Eagle RC, Sandy R, Gee W: Ocular pneumoplethysmography can help in the diagnosis of giant cell arteritis. Arch Ophthalmol 1989, 107: 379-81.

${ }^{8}$ Horven I: Dynamic tonometry IV: The corneal indentation pulse in giant cell arteritis. Acta Ophthalmol 1970, 48: 710-18.

${ }^{9}$ Bienfang DC: Loss of the ocular pulse in the acute phase of temporal arteritis: Acta Ophthalmol 1989, 67: (Suppl 191): 35-37.

${ }^{10}$ Henkind P, Charles NC, Pearson J: Histopathology of ischemic optic neuropathy. Am J Ophthalmol 1970, 69: 78-90.

${ }^{11}$ Silver DM, Farrell RA, Langham ME, O'Brien V, Schilder P: Estimation of pulsatile ocular blood flow from intraocular pressure. Acta Ophthalmol 1989, 67 (Suppl 191): 25-9.

${ }^{12}$ Langham ME, Farrell RA, O'Brien V, Silver DM, Schilder P: Blood flow in the human eye. Acta Opthalmol 1989, 67 (Suppl 191): 9-13.

${ }^{13}$ Eisenlohr J, Langham ME, Maumenee AE: Manometric studies of the pressure/volume relationships in living and enucleated eyes of individual subjects. Br J Ophthalmol 1962, 46: 536-48.

${ }^{14}$ Beck RW, Savino PJ, Repka MX, Schatz NJ, Sergott $\mathrm{RC}$ : Optic disc structure in anterior ischemic optic neuropathy. Ophthalmol 1984, 91: 1334-7.

${ }^{15}$ Beck RW, Servais GE, Hayreh SS: Anterior ischemic optic neuropathy IX Cup-to-disc ratio and its role in pathogenesis. Ophthalmology 1987, 94: 1503-8.

${ }^{16}$ Feit RH, Tomsak RL, Ellenberger C: Structural factors in the pathogenesis of ischemic optic neuropathy. Am J Ophthalmol 1984, 98: 105-8.

${ }^{17}$ Hayreh SS: Anterior Ischaemic Optic Neuropathy. VIII. Clinical Features and Pathogenesis of psthaemorrhagic amaurosis. Ophthalmology 1987, 94: 1488-502.
${ }^{18}$ McDonald WI and Sanders MD: Migraine complicated by ischaemic papillopathy. Lancet 1971, ii: 521-3.

${ }^{19}$ Tomsak RL: Ischaemic optic neuropathy associated with retinal embolism. Am J Ophthalmol 1985, 99: 590-2.

${ }^{20}$ Portnoy SL, Beer PM, Packer AJ, Van Dyk HJL: Embolic anterior optic neuropathy. J Clin Neuroophthalmol 1989, 9: 21-5.

${ }^{21}$ Lieberman MF, Shahi A, Green R: Embolic Ischaemic optic neuropathy. Am J Ophthalmol 1978, 86: 206-10.

${ }^{22}$ Hayreh SS: Anterior ischaemic optic neuropathy IV. Occurence after cataract extraction. Arch Ophthalmol 1980, 98: 1410-16.

${ }^{23}$ Repka MD, Savino PJ, Schatz NJ, Sergott RC: Clinical profile and long-term implications of anterior ischemic optic neuropathy. Am J Ophthalmol 1983, 96: 478-83.

${ }^{24}$ Guyer DR, Miller NR, Auer CL, Fine SL: The risk of cerebrovascular disease in patients with anterior ischemic optic neuropathy. Arch Ophthalmol 1985, 103: 1136-42.

${ }^{25}$ Olver JM, Spalton DJ, McCartney ACE: Microvascular structure of the retrolamina optic nerve in man: the possible significance in anterior ischaemic optic neuropathy. Eye 1990,4:7-24.

${ }^{26}$ Hayreh SS: Blood supply of the anterior optic nerve. In Ritch R, Shields, MB, Krupin T eds. The Glaucomas, St Louis: CV Mosby 1989, 133-161.

${ }^{27}$ Williams BI, Peart WS, Letley E: Abnormal intraocular pressure control in systemic hypertension and diabetes mellitus. Br J Ophthalmol 1980, 64: 845-51.

${ }^{28}$ Quigley HA and Langham ME: Comparative intraocular pressure measurements with the pneumatonograph and Goldmann tonometer. Am J Ophthalmol 1975, 80: 266-73.

${ }^{29}$ To'mey KF, Faris BM, Jalkh AE, Nasr AM: Ocular pulse in high myopia: a study of 40 eyes. Ann Ophthalmol 1981, 13: 569-71.

${ }^{30}$ Perkins ES: The ocular pulse. Curr Eye Res 1981, 1: 19-23. 